\title{
Aspectos Históricos sobre o Desenvolvimento da Ciência e da Tecnologia de Polímeros
}

A comunidade de profissionais que trabalha na área de polimeros tem crescido significativamente nestes últimos tempos no Brasil. Alguns profissionais formaram-se especificamente para trabalhar nesta área enquanto outros se adequaram à ela ao longo de sua carreira profissional. Apesar do acentuado desenvolvimento tecnológico nas áreas de plásticos, borrachas e fibras, pouco é conhecido historicamente sobre o surgimento destes materiais e sua evolução científica e tecnológica. Considerando que o conhecimento histórico sobre a origem e a evolução deste tema faça parte da capacitação cultural da comunidade de polímeros no Brasil, reservou-se um espaço nesta seção editorial para mostrar alguns aspectos históricos sobre o desenvolvimento da ciência e tecnologia de polímeros. As informações contidas nesta matéria foram retiradas do livro "Polymers : The Origins and Growth of a Science", escrito por H. Morawetz, publicado pela primeira vez em 1985 pela editora John Wiley \& Sons e reeditada em 1995 pela editora Dover.

A evolução da humanidade, desde seus primórdios, está intimamente ligada à capacidade do Homem em criar alternativas para garantir sua sobrevivência e melhorar seu conforto de vida. Assim, é possível observar constantes avanços científicos e tecnológicos nas áreas de alimentação, da saúde, de comunicação, de transporte, etc., para atingir tais objetivos. Grande parte das mudanças ocorridas até os dias de hoje se deve à disponibilidade de materiais adequados para transformar as idéias, e mesmo sonhos, em realidade. Esta correlação é tão significativa que a evolução do ser humano na face da Terra é cronologicamente registrada através de épocas designadas pelos materiais disponíveis até então, tais como, Idade da Pedra, Idade do Bronze, Idade do Ferro, etc.

Neste último século grande parte das mudanças tecnológicas realizadas pelo Homem se deve ao surgimento dos polímeros como material alternativo. Assim, borrachas sintéticas, plásticos e fibras sintéticas revolucionaram o desenvolvimento dos setores automotivos, eletro-eletrônicos, têxteis, de embalagens, da medicina, etc. A importância dos polímeros como materiais disponíveis para a transformação tecnológica deste século é tal que não seria exagero considerar a hipótese que algum historiador no futuro venha a designar este período, cronologicamente, como a Idade dos Polímeros, em analogia às épocas anteriores. Para garantir que isto não seja nenhum absurdo basta imaginar como seria o atual estágio de desenvolvimento tecnológico se os polímeros sintéticos não fossem disponíveis. Certamente as características de materiais similares como madeira, papel, borracha natural e fibras na- turais não seriam suficientes para suprir as necessidades.

Apesar dos materiais poliméricos terem revolucionado o desenvolvimento tecnológico deste século, seu surgimento, do ponto de vista científico, ocorreu na segunda metade do século passado. O termo polímero foi criado pelo famoso químico alemão J. Berzelius em 1832. $\mathrm{Na}$ realidade Berzelius tentou criar um termo para diferenciar moléculas orgânicas que possuíam os mesmos elementos químicos mas não necessariamente as mesmas propriedades químicas, como por exemplo os gases etileno e buteno. Inicialmente estas moléculas foram chamadas de isoméricas e posteriormente Berzelius esclareceu que as moléculas de buteno, possuindo 4 átomos de carbono e 8 átomos de hidrogênio, seriam o estado polimérico das moléculas de etileno, que em sua opinião possuíam 1 átomo de carbono e 
2 átomos de hidrogênio. Assim, o termo polímero foi utilizado para representar as moléculas de buteno como sendo constituídas de muitas (poli) unidades(meros) de etileno. Vale a pena ressaltar que nesta época não se conhecia o conceito de macromoléculas, que só veio a ser estabelecido em meados do século XX através de Hermann Staudinger. Anos mais tarde, em 1866, P. E. M. Berthelot utilizou o termo polímero dentro do mesmo contexto de Berzelius, ou seja, acetileno poderia ser convertido em polímeros chamados benzeno e estireno através de aquecimento. O termo polímeros só veio a ser usado como é conhecido hoje após 1922.

As primeiras experiências realizadas pelos cientistas do século passado com substâncias poliméricas envolviam polímeros naturais tais como borracha natural, amido, celulose e proteínas. Apesar da borracha natural ser menos abundante que a celulose e as proteínas, ela foi muito importante do ponto de vista histórico para a Ciência de Polímeros. As suas propriedades elásticas eram tão diferentes dos sólidos até então conhecidos que muitas pesquisas sobre a borracha natural foram realizadas por simples curiosidade. O próprio descobridor da América, Cristóvão Colombo, ficou intrigado com comportamento da borracha natural e escreveu para o rei da Espanha contando que havia observado uma brincadeira interessante entre os nativos do Haiti. Uma bola feita de uma resina que brotava de uma árvore, era jogada entre os nativos e pulava de um lado para outro com grande elasticidade. Em 1826 M. Faraday fez uma análise química elementar da borracha natural e encontrou uma razão em peso de 6,8 entre átomos de carbono e de hidrogênio $(\mathrm{C} / \mathrm{H})$. Hoje se sabe que esta relação é de 7,5. Em 1857 Lord Kelvin publicou um trabalho teórico analisando o comportamento de determinados sólidos sob efeitos térmicos. Foi relatado que uma tira de borracha da Índia, quando estirada rapidamente aquecia-se instantaneamente, ou melhor, fornecia calor para o ambiente, enquanto o processo reverso ocorria à medida que a tira retornava rapidamente ao seu tamanho original. Nesta mesma época Charles Goodyear conseguiu desenvolver o processo de vulcanização da borracha natural tornando possível o seu uso mais apropriado em aplicações onde a sua elasticidade fosse imprescindível.

O início da indústria de polímeros ocorreu basicamente com o domínio da tecnologia de vulcanização da borracha natural. Este material já era utilizado em determinadas aplicações, mas suas características pegajosas com o aumento de temperatura e a inexistência do processo de vulcanização, limitavam em muito seu uso até então. Em 1844 Goodyear conseguiu patentear o seu processo de vulcanização na França, entretanto no mesmo ano, mais precisamente um mês antes, Thomas Hancock patenteou um processo semelhante de vulcanização na Inglaterra. Até hoje existe uma controvérsia sobre o verdadeiro inventor de tal processo. $\mathrm{O}$ impacto da descoberta do processo de vulcanização foi tal que o consumo de borracha natural em 1830 , antes do desenvolvimento da vulcanização, era em torno de 25 toneladas passou para 6000 ton. em 1860 . O consumo cresceu ainda mais com $\mathrm{o}$ advento de fabricação dos pneus e câmaras de ar a partir de 1912. A celulose foi também responsável pelo início da indústria de polímeros. A nitretação da celulose foi o passo inicial para transformar a celulose em material aplicável, entretanto a plasti- ficação desde produto com cânfora expandiu o seu uso. Em 1870 os irmãos Hyatt patentearam o processo de plastificação do nitrato de celulose, cujo nome comercial passou a ser conhecido como celluloid. Inúmeras aplicações deste produto se iniciaram desde então tais como bolas de bilhar, dentaduras, escova de dente, pentes, bonecas, etc. Em meados do século XX a celulose foi transformada em fibras têxteis através de um processo de regeneração de celulose conhecido como processo viscose. Até então a industrialização de polímeros havia se caracterizado pela modificação de polímeros naturais. Somente em 1907 Lord Baekeland patenteou o processo de síntese de um material polimérico essencialmente sintético, ou seja, a resina fenolformaldeído conhecida popularmente como resina fenólica e comercialmente como resina Bakelite, em homenagem a seu inventor. $\mathrm{O}$ próprio Baekeland fundou duas empresas para produzir comercialmente esta nova resina sintética, ou seja, a Bakelit-Gesellschaft, na Alemanha, e a General Bakelite Company nos Estados Unidos da América.

Apesar da industrialização de polímeros ter se iniciado no final do século passado, o conhecimento específico sobre a Ciência de Polímeros era ainda muito incipiente. Não havia ainda uma consciência sobre a estrutura macromolecular dos polímeros. Somente em torno de 1920 um jovem pesquisador, Hermann Staudinger, professor de química orgânica do Instituto Federal de Tecnologia (ETH) em Zurique, decidiu dedicar a estudos de macromoléculas para compreender melhor o comportamento dos compostos orgânicos conhecidos até então como " high molecular compounds". A tese mencionada pela primeira vez em 1917 
por Staudinger, na qual os compostos orgânicos como a borracha natural, a celulose e o amido possuíam cadeias poliméricas como moléculas, foi muito contestada pelos pesquisadores da época. Em 1922 Staudinger utilizou polímeros sintéticos tal como poliformaldeído, ou melhor, poli(óxido de metileno) para simular o comportamento das macromoléculas de amido. Sua contribuição tornou-se mais significativa quando previu que as moléculas poliméricas poderiam se cristalizar, mesmo possuindo elevados pesos moleculares. Mesmo mostrando evidências experimentais sobre as características moleculares das substâncias poliméricas, Staudinger foi, muitas vezes, severamente criticado por importantes pesquisadores da época. A importância do trabalho sobre o conceito de polímeros, realizado por Staudinger, só foi reconhecido muitos anos mais tarde quando recebeu o prêmio Nobel de Química em 1953.

O desenvolvimento de novas técnicas de caracterização nos anos que se seguiram, tais como Ultracentrifugação, Viscosimetria de Soluções e Espalhamento de Luz, puderam elucidar de uma forma mais convincente alguns aspectos sobre a Ciência de Polímeros. Possuindo uma melhor compreensão sobre as características moleculares dos polímeros, foi possível dominar as técnicas de polimerização. Este foi o ponto de partida para o surgimento de inúmeros novos tipos de polímeros, satisfazendo novas aplicações. Staudinger e Wallace H. Carothers foram os pioneiros no desenvolvimento das técnicas de polimerização. Carothers se dedicou mais especificamente ao estudo de policondensação, enquanto Staudinger se dedicou ao estudo sobre poliadição. Em 1928 Carothers foi contratado pela empresa DuPont para desenvolver pesquisas idealizadas e lideradas por ele mesmo, sem urgência de aplicação imediata. Carothers dedicou seus primeiros anos na DuPont estudando a síntese de poliésteres alifáticos. Mesmo desenvolvendo fibras destes poliésteres ele acabou desistindo da pesquisa pois a temperatura de fusão destes materiais era relativamente baixa. Simultaneamente Carothers estudou a síntese de poliamidas e, em 1935 anunciou o desenvolvimento da síntese do Nylon 6,6. Em 1934, J.P. Flory havia sido contratado para trabalhar como membro da equipe liderada por Carothers. Poucos anos mais tarde, em 1937, Carothers comete suicídio. Apesar da perda a DuPont prossegue suas pesquisas e em 1938 anuncia no New York Times o desenvolvimento de fibras têxteis de Nylon 6,6, como a fibra de seda sintética. A importância do trabalho de Carothers sobre a síntese de poliésteres só foi reconhecida quando em 1946 J.R. Whinfield anunciou que a condensação de etileno glicol e ácido tereftálico proporcionava um poliéster aromático com elevada temperatura de fusão, ou seja, o PET, que poderia ser utilizado como fibra têxtil. Outro trabalho importante na área de policondensação foi realizado por O. Bayer que em 1947 anunciou a síntese do poliuretano elastomérico constituído de blocos rígidos e macios. A caracterização deste polímero apresentou novas perspectivas para a melhor compreensão de morfologias e microestruturas de borrachas termoplásticas.

O trabalho de Staudinger sobre o conceito de polímeros quase sempre se referia a substâncias de elevado peso molecular que, na sua opinião, não poderiam ser produzidas por policondensação. Esta é a principal razão pela qual ele não se interessou por este tipo de polimerização. Seus estudos tiveram como ênfase a poliadição e em 1929 publicou detalhes importantes sobre a polimerização de poliestireno. Staudinger chegou à conclusão que os monômeros deveriam atingir um estado de ativação energético para iniciar o crescimento da cadeia polimérica, ou seja, foi descoberta a importância do uso de iniciadores na síntese através da poliadição. Em 1934, Karl Ziegler publica um artigo utilizando o iniciador lítio butílico para polimerizar butadieno, ou seja, um composto organo-metálico como iniciador. Este advento foi o início do desenvolvimento de catalisadores estéreo-específicos para a síntese de poliolefinas tais como polietileno, polipropileno, etc. O fato pitoresco sobre a descoberta iniciada por Ziegler é que ele não estava interessado em sintetizar polímeros mas sim compostos organo-metáli$\cos$. Ao tentar realizar a reação entre trietil alumínio e hidreto de lítio para produzir tetra etil-lítio-alumínio, utilizou etileno como catalisador e quase que por acidente proporcionou a polimerização do etileno em baixas pressões. Em 1954, G. Natta, em parceria com a empresa Montecatini, tenta usar o mesmo tipo de catalisador para polimerizar propileno. Em 1963, Natta divide o prêmio Nobel de química com Ziegler pela importante contribuição no desenvolvimento de catalisadores estéreo-específicos para sintetizar poliolefinas, os conhecidos catalisadores do tipo Ziegler-Natta.

As décadas de 20 e 30 foram extremamente importantes para o estabelecimento dos conceitos básicos sobre Ciência de Polímeros através da participação de Staudinger, Carothers, Flory e outros. As décadas seguintes de 40, 50 e 60 foram igualmente importantes para o de- 
senvolvimento tecnológico da síntese de novos polímeros. Em 1960 surgem vários periódicos especializados em polímeros entre eles Journal of Polymer Science, Makromolekulare Chemie e Polymer. Desde então vários outros periódicos especializados surgiram na comunidade a saber Journal of Polymer Engineering and Science (1961), European Polymer Journal (1965), Journal of Macromolecular Science (1967), Macromolecules (1968) e outros. O avanço científico e tecnológico na área de polímeros teve seu reconhecimento através da concessão de vários prêmios Nobel na área de química entre eles Staudinger (1953), Ziegler e Natta (1963), Flory (1974) e Merrifield (1984) na área de biopolímeros. Outros pesquisadores de vanguarda que contribuíram destacadamente para a área de polímeros são Hermann Mark, H.W. Melville, J. D. Ferry, C. S. Marvel, W. Kuhn, G.V. Schulz e o pioneiro W. H. Carothers.

Pode-se considerar a história da Ciência e Tecnologia de Polímeros bastante recente, principalmente se comparada com a dos materiais tradicionais como metais e cerâmicas. Muitos desafios encontram-se em andamento nas áreas de $\mathrm{C} \& \mathrm{~T}$ de polímeros, principalmente o desenvolvimento de propriedades que venham a ampliar sua aplicação em diversos campos tecnológicos. Assim, existem esperanças que o polímero intrinsecamente condutor elétrico venha a revolucionar a tecnologia de veículos movidos por baterias elétricas. Da mesma maneira as indústrias automotivas, eletro-eletrônicas e de embalagens continuam a substituição de materiais tradicionais por materiais poliméricos desenvolvidos com novas propriedades desejadas. Os profissionais que hoje atuam nos vários setores de polímeros certamente têm observado que o surgimento de polímeros sintéticos nas primeiras décadas deste século contribuiu em muito para a revolução tecnológica pela qual passamos atualmente.

Início de Comercialização de Alguns Polímeros Sintéticos*

\begin{tabular}{|c|c|c|c|}
\hline Ano & Sigla & Polímero & Fabricante \\
\hline 1927 & PVC & Poli(cloreto de vinila) & B. P. Goodrich \\
\hline 1930 & PS & Poliestireno & I.G.Farben/Dow \\
\hline 1936 & PMMA & Poli(metacrilato de metila) & Rohm and Haas \\
\hline 1936 & PA 6,6 & Nylon 6,6 & DuPont \\
\hline 1939 & LDPE & Polietileno de Baixa Densidade & ICI \\
\hline 1946 & PTFE & Poli(tetra fluor etileno)/TEFLON & DuPont \\
\hline 1948 & ABS & Copolímero acrilonitrila-butadieno-estireno & Rohm and Haas/ I.G.Farben \\
\hline 1954 & PU & Poliuretanos & Bayer/DuPont \\
\hline 1954 & HDPE & Polietileno de Alta Densidade & Hoechst \\
\hline 1954 & PET & Poli(tereftalato de etileno) & ICI \\
\hline 1956 & PA 6 & Poliamida ou Nylon 6 & Allied \\
\hline 1957 & PP & Polipropileno & Phillips Petrol. \\
\hline 1958 & $\mathrm{PC}$ & Policarbonato & GE/Bayer \\
\hline 1958 & POM & Poliacetal ou Acetal & DuPont \\
\hline 1959 & LLDPE & Polietileno Linear de Baixa Dens. & DuPont-Canada \\
\hline 1960 & ARAMID & Poli(amida aromática) & DuPont \\
\hline 1963 & PI & Poliimidas & DuPont \\
\hline 1965 & PPO & Poli(eter fenileno) ou Noryl & GE \\
\hline 1965 & SBS & Borracha Termoplástica & Shell \\
\hline 1969 & PBT & Poli(tereftalato de butileno) & Celanese \\
\hline 1972 & PPS & Poli(sulfeto de fenileno) & Phillips Petrol. \\
\hline 1972 & LCP & Cristal Líquido Polimérico & Carborundum \\
\hline 1978 & PES & Poli(éter sulfona) & ICI \\
\hline 1978 & PEEK & Poli(éter éter sulfona) & ICI \\
\hline 1982 & PEI & Poli(éter imida) & GE \\
\hline 1987 & PA 4,6 & Poliamida ou Nylon 4,6 & DSM \\
\hline
\end{tabular}

* Dados obtidos através da referência : UTRACKI, L.A. - " History of commercial polymer alloys and blends". Polym. Eng. Sci. , vol. 35, pag. 2, 1995 